\title{
Neuroendocrine tumors of the gallbladder (Review)
}

\author{
CHUNYUAN NIU, SHUPENG WANG, QINGCHUN GUAN, XUEKANG REN, BAI JI* and YAHUI LIU* \\ Department of Hepatobiliary and Pancreatic Surgery, The First Hospital of Jilin University, \\ Changchun, Jilin 130021, P.R. China
}

Received October 12, 2019; Accepted February 13, 2020

DOI: $10.3892 / \mathrm{ol} .2020 .11461$

\begin{abstract}
A gallbladder neuroendocrine neoplasm (GB-NEN) is a unique heterogeneous neoplasm, originating from neuroendocrine cells and able to secrete peptides as its neurotransmitter. Among all the neuroendocrine tumors (NETs), the GB-NEN prevalence is $0.5 \%$, which accounts for $\sim 2.1 \%$ of all gallbladder tumors. The current study aimed to present an up-to-date review of the clinical features, diagnosis and treatment of NETs of the gallbladder. A systematic literature search was performed in order to identify all relevant studies published. Thus far, the etiology and pathogenesis of GB-NEN remains unclear. Moreover, an ambiguous clinical manifestation exists as observed during laboratory examinations. As GB-NEN is a rare gallbladder lesion and is seldom seen in clinical practice, there is a limited availability of review reports, and it is therefore often considered only as a case study. It is difficult to distinguish GB-NEN from other gallbladder diseases using imaging diagnostic techniques. Although chemotherapy treatment provides prolonged progression-free survival, surgery is considered the best option. Thus, to overcome the inherent risks or shortfalls of traditional surgery; early detection, diagnosis and treatment of GB-NEN are required to improve patient longevity.
\end{abstract}

Correspondence to: Dr Yahui Liu or Dr Bai Ji, Department of Hepatobiliary and Pancreatic Surgery, The First Hospital of Jilin University, 71 Xinmin Street, Changchun, Jilin 130021, P.R. China E-mail:3106622502@qq.com

E-mail: jirulin@sina.com

*Contributed equally

Abbreviations: GB-NEN, gallbladder neuroendocrine neoplasm; VEGF, vascular endothelial growth factor; NET, neuroendocrine tumor; NEC, neuroendocrine carcinoma; CT, computed tomography; MRI, magnetic resonance imaging; NSE, neuron-specific enolase; Syn, synaptophysin; CHG-A, pheochromin-A; 5-HIAA, 5-hydroxyindole-acetic acid

Key words: pathological classification, neuroendocrine tumor of the gallbladder, clinical features, diagnosis, treatment

\section{Contents}
1. Introduction
2. Epidemiology
3. Causes
4. Molecular mechanisms
5. Pathological classification
6. Clinical manifestations
7. Diagnosis
8. Differential diagnosis
9. Treatment options
10. Prevention
11. Prognosis
12. Conclusion

\section{Introduction}

A neuroendocrine neoplasm (NEN) is a type of heterogeneous tumor, which was first reported and identified as carcinoid by Oberndorfer in 1907. A NEN originates and spreads from neuroendocrine cells and peptidergic neural crest Kulchitsky cells (silver-addicted cells) (1). These cells perform essential biochemical functions such as the uptake of amine precursors, decarboxylation, and the release of bioactive peptide hormones and nerve mediators (2). As the occurrence of gallbladder NEN (GB-NEN) is low, it is difficult to obtain clear and large amounts of data on the etiology, pathogenesis, standard treatment plan and prognosis from large-scale studies conducted at multi-center research centers. As there is no standard procedure to identify and treat GB-NENs, the present study reviews the current clinical characteristics, diagnosis and treatment regimens available for patients with GB-NEN in order to better our understanding of the condition.

\section{Epidemiology}

The incidence of NEN is rare in clinical practice, it has been observed in only 115/100,000 cases worldwide in the last decade, which accounts for $1.25 \%$ of all malignancies (3). The average age of onset is 60 years and the majority of NENs are found in the gastrointestinal tract (66\%), followed by the lungs (31\%) (4). A hierarchical pattern of prevalence of NENs is found within the gastrointestinal tract, with increasing numbers found from the appendix, to the small intestine, to the rectum and finally to the colon. Although the occurrence of NENs is rare in the stomach and other parts of the gastrointestinal system, the ovaries, 
pancreas and testicles can be affected; however, occurrence in the liver and gallbladder is rare (5). Among all gastrointestinal carcinoids, extrahepatic biliary carcinoids account for $0.5-2.0 \%$ of cases and liver metastases remain common $(6,7)$. Surveillance Epidemiology and End Result (SEER) research data indicate that GB-NENs account for $0.5 \%$ of all NETs and $2.1 \%$ of all gallbladder tumors (8). There are only a few reports available in the literature about GB-NENs and even fewer on cholecystic neuroendocrine carcinoma. From previous studies, there were three groups of large data reported, including two groups from Korea with 6 and 12 cases (9), respectively. The third group was from China with 10 cases (10). In addition to the above 10 cases, most of the literature in available in China about GB-NENs are individual case reports.

\section{Causes}

To identify the root cause of the GB-NEN, a thorough examination and understanding of the cellular nature of the disease is important. In the process of examination, minimal neuroendocrine cells can be found on the gallbladder mucosa, if any exist in this space (11-13). Further GB-NEN etiological identifiers may be as follows: i) The undifferentiated gallbladder stem cells separate into neuroendocrine cells. ii) The presence of gallbladder stones results in chronic inflammation of the gallbladder mucosa causing intestinal epithelium or gastric metaplasia, which are considered to be pathological metaplasia. In an advanced stage, this inflammation produces neuroendocrine cells at the lesion site eventually leading to the development of a GB-NEN $(12,14,15)$. iii) In certain situations, the gallbladder adenocarcinoma function switches to a neuroendocrine one, resulting in chronic inflammation of gallbladder tissues and formation of stones, further exacerbating the other risk factors for gallbladder adenocarcinoma.

\section{Molecular mechanisms}

Despite inadequate understanding of the etiology and pathogenesis of GB-NENs, significant progress has been made in elucidating the molecular and biological pathways involved. These results encourage the creation of follow-up studies for the identification of novel diagnostic and treatment procedures for the disease. It has been confirmed in two previous studies $(15,16)$ that activation of the epidermal growth factor receptor (EGFR) can upregulate downstream effector protein kinase B and extracellular signal regulate kinase expression (Fig. 1). Concurrently, the target protein of rapamycin in human cells regulates the growth, proliferation and motor activity of the cells. The expression levels of this protein and the proliferation index of the cells were determined to be positively correlated (13). The high expression of the aforementioned three molecules (the target protein of rapamycin, protein kinase B and extracellular signal regulate kinase) resulted in a poor prognosis in patients with GB-NENs (13). Scoazec described that angiogenesis serves an important role in NEN etiology and pathogenesis (17). It is also possible to treat NEN and prolong the survival of patients with the disease by blocking the high expression of vascular endothelial growth factor (VEGF) and its receptor. However, no specific mechanism backed by concrete evidence has been discovered to date for GB-NENs.

\section{Pathological classification}

There are three pathological classifications of GB-NEN: Carcinoid or typical carcinoid(low malignancy), atypical carcinoid(moderate malignancy) and small cell carcinoma (high malignancy). These classifications are based on GB-NEN histopathological structure, cell morphology and degree of differentiation, mitotic combination, and necrotic and biological behavior (18). Morphologically, the majority of neuroendocrine tumor (NET) cells are small, cone-shaped and polygonal, with no clear cell boundaries (18). GB-NEN cells have small nucleoli, granular chromatin, and relatively consistent tumor cell morphology, and are rich in interstitial blood vessels (19). According to the classification criteria of digestive system tumors by the World Health Organization in 2010, the well-differentiated NETs include grades G1 and G2, and the poorly differentiated NET (G3) is defined as a neuroendocrine carcinoma (NEC). The NEC is further classified based on the tumor cell size into large or small. G1 contains both the NEC and adenocarcinoma tumors and is therefore identified as a mixed gland neuroendocrine carcinoma (18).

The extrahepatic bile ducts and the ampullary region are more commonly observed in a GB-NEC of high malignancy, poor prognosis and little to no pathological differentiation (20). The occurrence of early metastasis is mainly identified through local infiltration and lymph node metastasis (21). The lymph nodes, liver, lungs and peritoneum are the most common metastasis sites of small cell GB-NEC (22). The American Cancer Institute Research reported 41 cases of gallbladder NEC of varying pathological grades between 1973 and 2005. The data revealed that high, medium and low/no differentiation pathological grade accounted for $2.4,7.3$ and $89.7 \%$ of the cases, respectively (8).

The most common histological finding reported in gallbladder malignancy is adenocarcinoma (80-90\%) followed by undifferentiated carcinoma $(10 \%)$ and then squamous cell carcinoma/squamous adenocarcinoma (5\%). Overall, the occurrence of NEC is rare.

\section{Clinical manifestations}

According to case reports, the occurrence of GB-NEN is higher among women $(\sim 68 \%)$ of cases identified $(22,23)$. The majority of these patients do not have any manifestations of carcinoid syndrome (24). The majority of NECs in the gallbladder and extrahepatic bile duct are non-functional APUD (amine precursor uptake and decarboxylation) tumors, with low or no functional endocrine granules in tumor cells (25). Early clinical manifestations of NEC are similar to those of other types of gallbladder cancer and include abdominal distension pain, nausea and other non-specific symptoms (26). In order to distinguish from GB-NEC, symptoms specific to carcinoid syndrome include spasmodic abdominal pain, flushes, edema, wheezing, diarrhea and right heart valve disease, yet these account for only $1.0 \%$ of those symptoms reported in patients with NEC (26).

\section{Diagnosis}

The diagnosis of GB-NEN prior to surgery remains difficult. Currently, tumor markers and imaging examinations, such as ultrasound, computed tomography (CT) and magnetic resonance imaging (MRI), are used. Limitations of the 


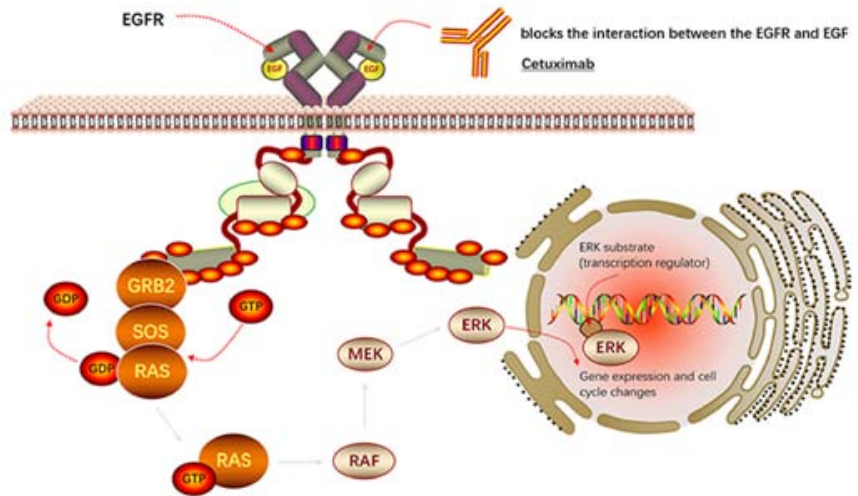

Figure 1. Inhibitor (Cetuximab) of EGFR signaling in GB-NEN. Cetuximab blocks the interaction between the EGFR and EGF, thereby inhibiting the activation of downstream RAS-ERK and thereby blocking the occurrence of GB-NEN. EGF is a polypeptide molecule and EGFR is a typical receptor protein PTK. The signal transduction process of EGFR is: i) EGFR forms a dimer to change the conformation, PTK activity is enhanced, through self-phosphorylation of the receptor intracellular tyrosine residues phosphorylation. ii) EGFR phosphorylated by tyrosine binds to GRB2. iii) GRB2 activates RAS by collecting SOS, a positive regulator of RAS, promoting the release of GDP and binding to GTP. iv) Activated RAS (RAS-GTP) acts on RAF to activate it. Activated RAF acts on MEK, which acts on ERK to activate it. v) The activated ERK is translocated to the nucleus, which affects the expression of target genes and promotes the generation of GB-NEN. EGF, epidermal growth factor; EGFR, epidermal growth factor receptor; GRB2, growth factor receptor-bound protein 2; SOS, son of sevenless; GDP, guanine diphosphate; GTP, guanine triphosphate; MEK, mitogen-activated protein kinase; GB-NEN, gallbladder neuroendocrine neoplasm.

current techniques hinder the proper diagnosis of patients with GB-NENs. For instance, tumor markers that include carbohydrate antigen (CA)19-9, carcinoembryonic antigen and CA125 are often negative (27). Ultrasound examination detects only the thickening of gallbladder walls, gallbladder swelling-type lesions and a low echoic nodule (Fig. 2). CT and MRI examination generate impressions indicating that GB-NEN typically presents a thickening of the cystic wall on one side, with the mass protruding into or out of the cavity (Fig. 3). These scans also indicate a visible necrotic shadow in larger lesions (28). In studies examining the results of CT and MRI scans in GB-NEN, it was noted that after the enhancement of GB-NEN, the lesion continued to strengthen and the enhancement was slightly more obvious compared with that of adenocarcinoma (29). Endoscopic retrograde cholangiography revealed the defect of the tumor in the gallbladder (Fig. 4). However, the presence of lymph node metastasis around the gallbladder and retroperitoneum is difficult to distinguish from the other gallbladder tumors (30). Imaging examinations provide significant results only when used at an early stage and then provide aid in establishing a treatment plan (31).

Diagnostic comparisons indicate that immunohistochemical staining is the most effective tool for the diagnosis of GB-NENs. Immunohistochemistry is divided into two parts (32). First, neuroendocrine cell markers such as neuron-specific enolase (NSE), synaptophysin (Syn), pheochromin-A (CHG-A), protein gene product and Rankine are positively detected (Fig. 5). Second, amines and amine hormones such as adrenocorticotropic hormone, growth hormone, human chorionic gonadotropin, 5-hydroxytryptamine, vasoactive polypeptide, insulin, gastrin, somatostatin,
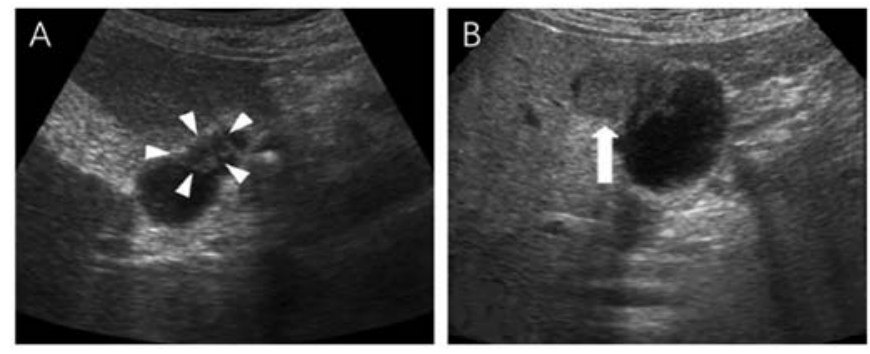

Figure 2. Ultrasonography images of GB-NEN. (A) Ultrasonography image presenting a $0.8-\mathrm{cm}$ low echoic nodule (arrowheads) in the neck of the gallbladder. (B) Ultrasonography image identifying a low echoic mass of $39 \times 30 \mathrm{~mm}$, with clear boundaries to the liver from the fundus of the gallbladder (arrowheads). GB-NEN, gallbladder neuroendocrine neoplasm.
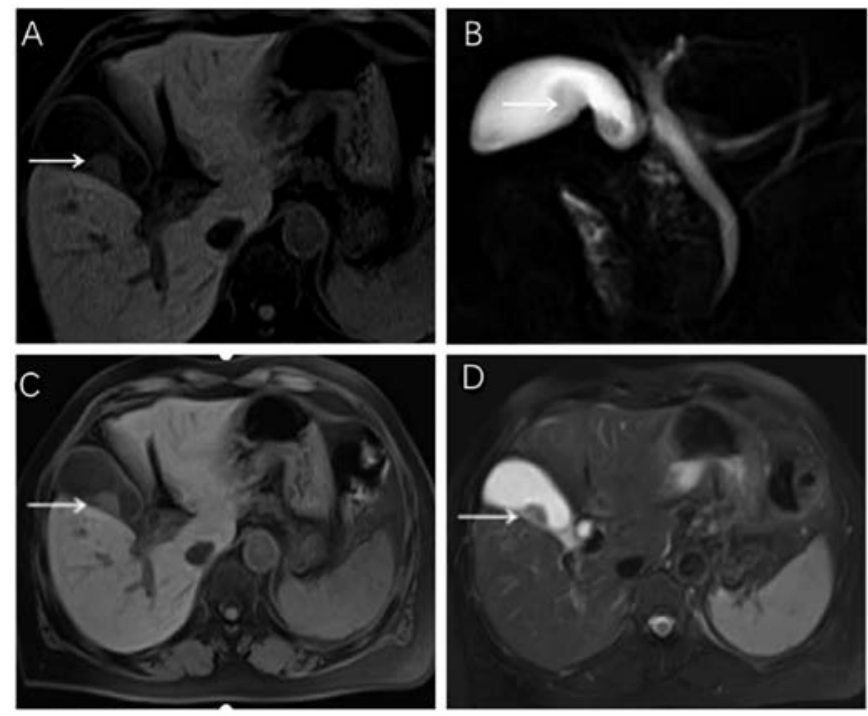

Figure 3. Magnetic resonance images of GB-NEN. A, B, C and D are presenting the same mass in the gallbladder, which was confirmed as GB-NEN by pathology. Arrows indicate neuroendocrine tumor of the gallbladder .GB-NEN, gallbladder neuroendocrine neoplasm.

pancreatic polypeptide and calcitonin can simultaneously trigger expression of other hormones (33). Among all of the previously mentioned hormones CHG-A, Syn and NSE have the highest specificity (34). A study has demonstrated that $\mathrm{CHG}-\mathrm{A}$ is a substance released by secretory particles in neuroendocrine cells to confer their secretory characteristics (35). Evidence demonstrated that the serum CHG-A level in $60-80 \%$ of patients with NEC of the digestive system was higher compared with that of normal patients (36). Therefore, the serum CHG-A test has the highest significance in the diagnosis of GB-NEN. Monier et al (37) further suggested that the urine detection of 5-hydroxyindole-acetic acid (5-HIAA) may aid in the diagnosis of GB-NEN. However, in this study, the positive rate reads were low due to the insufficiency or non-secretion of 5-HIAA in some patients with GB-NEN.

\section{Differential diagnosis}

Examination of patients presenting with GB-NEN symptoms and markers can identify differential disorders such as 


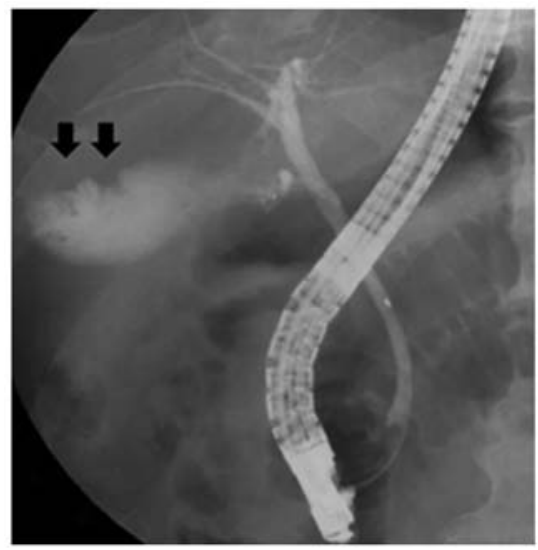

Figure 4. Endoscopic retrograde cholangiography demonstrating no abnormalities of the bile duct, but an observable tumor defect in the gallbladder (arrowheads).

cholestasis, gallbladder polyps, gallbladder adenomyosis and gallbladder adenoma. Apart from the pathological immunohistochemical examinations, contrast-enhanced ultrasonography has differential clinical significance (38). Case reports using contrast-enhanced ultrasonography have revealed that biliary sludge is not enhanced (39) .In these case reports, the gallbladder polyp was enhanced with grape-like fine pedicles and the three-layer structure of gallbladder wall was clear (40).For adenomyosis of the gallbladder, unenhanced vesiculoid echocardiography was observed and the inner and serous membranes of the gallbladder were intact (41). Gallbladder adenoma resulted in delayed enhancement that was identifiable by 'fast in and slow out' through the complete three-layer structure of the gallbladder wall (38). In conclusion, contrast-enhanced ultrasonography can improve the appearance of gallbladder carcinoma and facilitate an early differential diagnosis.

\section{Treatment options}

Surgical treatment. Advantages and disadvantages of the various treatment options discussed are listed in Table I: Due to its complexity, gallbladder cancer must be treated surgically by experienced biliary tract physicians and pathologists (42). GB-NEC is characterized by high malignancy, early lymphatic metastasis (the $\mathrm{N} 2$ lymph node metastasis rate is significantly higher compared with that of patients with adenocarcinoma in the same period) and a poor prognosis when compared with all other types of gallbladder cancer (20). Radical resection is considered to be the most effective and preferred method of surgical treatment for patients with GB-NEC (43). The purpose of a radical resection is to eliminate lesions, confirm a clear diagnosis, provide a basis for post-operative comprehensive treatment and improve the quality of life of affected patients (33). Surgical methods include simple, radical and expanded radical cholecystectomy, whereby the choice of surgical type is often discussed between the medical professional and patient (44). The progress made in recent years to expand the time period during which radical resection can be performed, including R0 resection for GB-NEC, has increased the overall long-term survival time of patients (31). With these
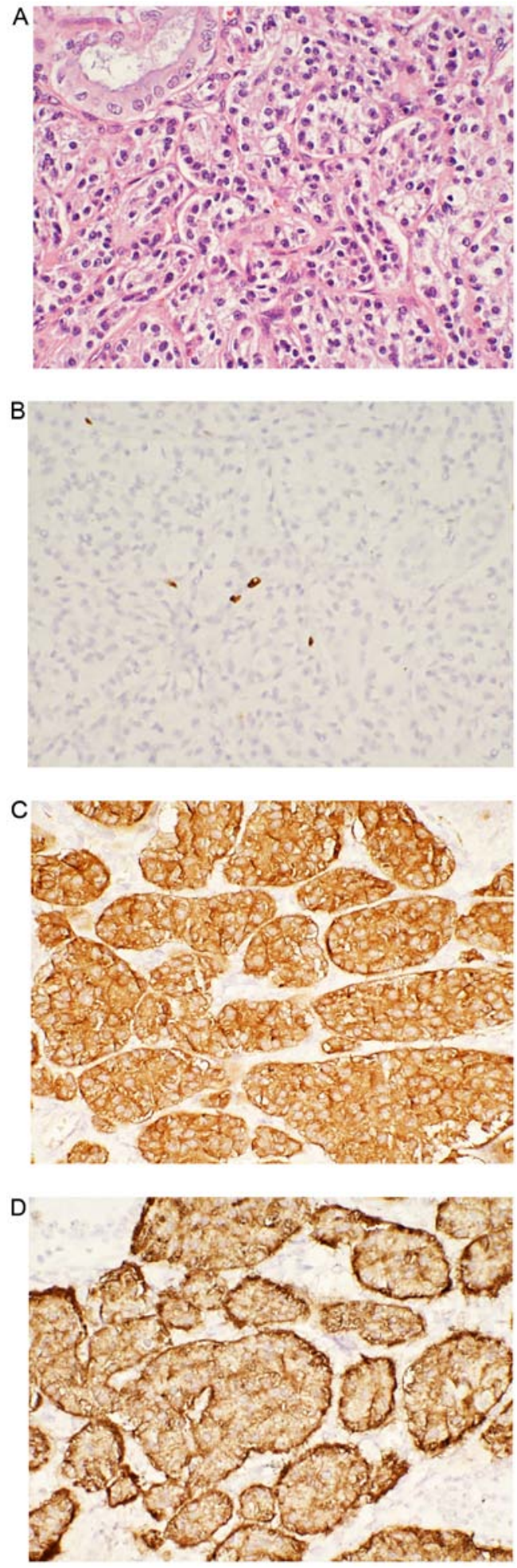

Figure 5. Histological examination of a gallbladder tumor. (A) Cellularity is very high with hyperchromatic nuclei and scant cytoplasm observed (H\&E stain) (magnification, x40). (B) Immunohistochemical staining of Ki-67. Tumor cells demonstrate a Ki-67 index $<1.0 \%$ (magnification, $x 40$ ). (C) Tumor cells demonstrate positive expression of synaptophysin (magnification, $\mathrm{x} 40$ ). (D) Positive expression of pheochromin-A is observed in tumor cells (magnification, $\mathrm{x} 40$ ).

promising results, expanded radical prostatectomy should also be attempted (45). Only under situations where the tumor invades the mucosa, submucosa or muscularis for GB-NET is simple cholecystectomy feasible (46). In the case of late-stage 
Table I. Comparison of advantages and disadvantages of different gallbladder neuroendocrine neoplasm treatment options.

\begin{tabular}{|c|c|c|}
\hline Treatment options & Advantages & Disadvantages \\
\hline Surgical treatment & $\begin{array}{l}\text { 1. Is the most effective treatment } \\
\text { 2. Eliminates lesions completely } \\
\text { 3. Makes the diagnosis clear } \\
\text { 4. Provides the basis for postoperative } \\
\text { comprehensive treatment } \\
\text { 5. Improves the quality of life and the } \\
\text { overall long-term survival rate }\end{array}$ & $\begin{array}{l}\text { 1. Needs experienced biliary physicians and pathologists } \\
\text { 2. Cholecystectomy alone is only feasible if the tumor } \\
\text { invades the mucosa, submucosa or muscularis }\end{array}$ \\
\hline Chemotherapy & $\begin{array}{l}\text { 1. An important alternative therapy } \\
\text { (for patients who are not suitable for } \\
\text { surgery) }\end{array}$ & $\begin{array}{l}\text { 1. Has limited effect for tumors with high differentiation } \\
\text { and slow growth }\end{array}$ \\
\hline & $\begin{array}{l}\text { 2. Prolongs the survival of patients } \\
\text { significantly }\end{array}$ & $\begin{array}{l}\text { 2. No unified standard chemotherapy treatment available } \\
\text { currently }\end{array}$ \\
\hline $\begin{array}{l}\text { Molecular targeted } \\
\text { therapy }\end{array}$ & $\begin{array}{l}\text { Prolongs progression-free survival and } \\
\text { overall survival times }\end{array}$ & $\begin{array}{l}\text { No molecular targeted drug therapy has been widely } \\
\text { recognized and used }\end{array}$ \\
\hline $\begin{array}{l}\text { Treatment with } \\
\text { somatostatin analogs }\end{array}$ & $\begin{array}{l}\text { 1. Inhibits tumor progression } \\
\text { 2. Improves symptoms and the overall } \\
\text { prognosis of patients }\end{array}$ & $\begin{array}{l}\text { Only effective with positive expression of the somatostatin } \\
\text { receptor }\end{array}$ \\
\hline $\begin{array}{l}\text { Radiotherapy and } \\
\text { interventional therapy }\end{array}$ & $\begin{array}{l}\text { 1. Inhibits tumor growth } \\
\text { 2. Interventional embolization of the } \\
\text { hepatic artery is an effective method to } \\
\text { treat hepatic metastasis }\end{array}$ & $\begin{array}{l}\text { The clinical efficacy and safety have not been determined } \\
\text { yet and need further study }\end{array}$ \\
\hline
\end{tabular}

occurrence without distant metastasis, cholecystectomy combined with local liver resection and lymph node clearance is an option for obtaining a good surgical margin (47). The aforementioned study strongly recommends performing radical resection to the maximum possible extent even when liver metastases are limited. If radical resection is not feasible, then volume reduction surgery must be considered as an effective follow-up treatment to improve the quality of life of patients with GB-NENs (48).

Chemotherapy. Patients with GB-NENs who are medically unfit for surgery must be given chemotherapy, a significant alternate treatment method (49). GB-NEC is highly invasive and develops early lymph node metastasis, hence surgery followed by radiotherapy and chemotherapy is recommended to help prolong the survival period of such patients (50). In the case of NEC with high differentiation and slow growth, the effect of chemotherapy has been observed to be limited (51). For rapidly growing tumors, chemotherapy response rates range from $20-60 \%$ worldwide (52). Based on the differing degrees of tumor differentiation, the most commonly used chemotherapy drugs include streptozotocin, 5-fluorouracil, adriamycin, cisplatin and etoposide (11). Due to the clinical incidence of GB-NEN being low, there are few associated studies available, which results in the lack of a unified standard chemotherapy program. Available studies have demonstrated that oxaliplatin plus gemcitabine is the most effective chemotherapy regimen for gallbladder cancer at present; however, cholecystic NEC has a poor response to this treatment. Therefore, chemotherapy drugs advocated for gastrointestinal and cholecystic NEC include etoposidem, cisplatin and Adriamycin (11). Associated case reports demonstrated that the post-operative use of gemcitabine, docetaxel, or cisplatin combined with cisplatin, sunitinib and docetaxel, respectively, resulted in a longer survival time in patients with GB-NENs $(53,54)$. Inoue et al $(55)$ reported that following combination treatment with cisplatin and irinotecan, the tumor size in a patient with GB-NEC was significantly reduced and the tumor-free survival period was significantly prolonged compared with cisplatin alone. In addition, in another study, it was reported that the response rate to etoposide and cisplatin increased up to $50-56 \%$ in poorly differentiated and rapidly growing NEC (56). In the cases investigated, a medium dose of 3-6 million units of $\alpha$-interferon was used 3-7 times a week as adjuvant therapy for NEC (56).

Molecular targeted therapy. To date, there is no molecular targeted drug therapy of note for the treatment of patients with GB-NENs. However, there are limited drug therapies available under review. A study has reported progression of the disease coupled with an increased level of VEGF in the blood of patients with GB-NEN (57). This indicates that VEGF-mediated neovascularization plays an important role in the occurrence, progression, metastasis and recurrence of GB-NEN. Raymond et al (58) and Yao et al (59) confirmed that the targeted drug sunitinib extends the progression-free survival $(\mathrm{P}<0.001)$ and the overall survival $(\mathrm{P}=0.02)$ rate of pancreatic NEN patients by resisting the binding of the vascular 
endothelial growth factor and platelet-derived growth factor receptors to the corresponding ligand. To develop this as an effective treatment option, the mechanism by which sunitinib acts in patients with GB-NEN requires detailed investigation.

Treatment with somatostatin analogs. Caplin et al (60) conducted a randomized control trial where the progression-free survival rate of patients with NEN treated with a somatostatin analog (octreotide) was significantly higher compared with that of the placebo group $(\mathrm{P}<0.05)$. Other studies by Igaz (61) and Oberg et al (62) confirmed the significance of somatostatin analogs (octreotide) in inhibiting tumor progression, and improving symptoms and overall patient prognosis. Meanwhile, Oberg et al (62) also described that with the emergence of long-acting drugs, patients are able treat themselves using monthly injections. This treatment method is effective for patients with positive expression of somatostatin receptor GB-NEN.

Radiotherapy and interventional therapy. The molecular mechanisms that underpin the clinical effect of radioactive isotopes of peptide receptors and the somatostatin analogs are similar (63). Local radiotherapy inhibits tumor growth through use of the radioactive isotopes Y90 or Lu177, with good clinical tolerance in patients with GB-NEN (64). In addition, adjuvant treatment of GB-NEN also includes interventional therapy, namely radiofrequency ablation, seed implantation, arterial embolization and laser hyperthermia. Among them, interventional embolization of the hepatic artery is found to be effective for hepatic metastasis (65). Embolization agents such as anhydrous ethanol or chemotherapy drugs have also been used for patients with GB-NEN; however, the clinical effects and safety of the aforementioned treatment methods require further investigation in detailed studies (66). In clinical practice, it is suggested that targeted treatment is performed in accordance with relevant guidelines and by keeping the specific condition of the patient in mind (67).

\section{Prevention}

NEC is a slow-growing malignant tumor without any specific clinical manifestations (68). Preoperative diagnosis often depends on the typical oncoid syndrome. Since GB-NEN and oncoid syndrome are not associated, patients typically visit the doctor only during middle- or late-stage presentation with metastasis (44). Therefore, to increase the diagnosis rate and prevent progression of GB-NEN, an appropriate treatment is advised following complete routine examination for all patients with chronic cholecystitis and cholecystolithiasis. The presentation of GB-NEN is further complicated by the presence of gallbladder stones (29). Stimulation of the gallbladder wall by stones (69) and the occurrence of GB-NEN are related. The complexity of the disease is further increased as GB-NEN is also associated with small intestinal carcinoid. Thus, regular examination is strongly recommended for the correct diagnosis (5). Both gastrointestinal and pulmonary carcinoid cancers result in calcification via dystrophic calcification and endocrine hormone stimulation (70). However, to the best of our knowledge, there are no national or international cases of patients with GB-NEN in which calcification has been reported, providing some level of distinction.

\section{Prognosis}

The prognosis of GB-NEN depends on the pathological type under investigation. Atypical carcinoid, low-differentiated adenocarcinoma and small-cell carcinoma. The prognosis, in general, is acceptable for patients with GB-NET, especially G1 disease, as there is a low degree of clinical malignancy with no obvious early metastasis. However, due to the high malignancy and rapid progress of GB-NEC, lymph node and liver metastasis occur simultaneously at diagnosis and lead to a poor prognosis in practice (71). A study has indicated that a lower Ki-67 index with smaller tumor volume leads to a better prognosis for GB-NEN (72). Conversely, the prognosis is worse when the tumor sizes vary and the symptoms are more complex (73). A study by the Memorial Sloan Kettering Cancer Center demonstrated that the median survival time of 13 patients with GB-NEC was only slightly shorter compared with that of 435 patients with gallbladder cancer (9.8 months vs. 10.3 months, respectively) (14). Chiorean et al (11) demonstrated that GB-NEC 1-, 2- and 3-year survival rates were lower compared with those of other types of gallbladder cancer (20 vs. $38 \%$; 10 vs. $31 \%$; 0 vs. $30.1 \%$, respectively) during the same period.

\section{Conclusion}

The current review demonstrates that GB-NEN is a relatively rare gallbladder lesion, unique in presentation and often relayed as a case study. Therefore, early detection, correct diagnosis and reasonable treatment of such tumors will help in extending the quality of life of affected patients. At present, the origin of GB-NEN is unclear, the clinical manifestations are atypical and the majority of laboratory and imaging examinations provide no specificity. The diagnosis of GB-NEN depends on pathological and immunohistochemical examinations utilizing markers such as Syn, NSE and CHG-A. In terms of treatment options, surgical treatment is the best choice and active multi-mode comprehensive treatment such as chemoradiotherapy, targeted therapy and somatostatin analogs also significantly prolong survival times in patients with GB-NEN. This review has certain limitations. Due to the low incidence and availability of studies, there is no uniform standard treatment identified for treating GB-NEN. Therefore, we suggest that treatment is provided on a case by case basis to comprehensively integrate the advantages of various treatment methods for providing targeted treatment and to maximize the benefits for patients with GB-NEN in clinical practice.

\section{Acknowledgements}

Not applicable.

\section{Funding}

The present study was supported by the National Natural Science Foundation of China (grant no. 81802805) and The 
Jilin Province Health Technology Innovation Project (grant no. 2017J047).

\section{Availability of data and materials}

The datasets used and/or analyzed during the current study are available from the corresponding author on reasonable request.

\section{Authors' contributions}

$\mathrm{CN}, \mathrm{YL}$ and BJ conceived and designed the study. CN,SW, QG and XR performed the literature searches and drafted the manuscript. All authors read and approved the final manuscript.

\section{Ethics approval and consent to participate}

Not applicable.

\section{Patient consent for publication}

Not applicable.

\section{Competing interests}

The authors declare that they have no competing interests.

\section{References}

1. Modlin IM, Lye KD and Kidd M: A 5-decade analysis of 13715 carcinoid tumors. Cancer 97: 934-959, 2003.

2. Naito S, Naito M, Yamamoto N, Kume T, Hosino S, Kinjyo Y, Naito Y, Naito $\mathrm{H}$ and Hasegawa S: Polypoid gallbladder neuroendocrine tumor diagnosed as benign polyp before surgery: A case report. Mol Clin Oncol 12: 225-229, 2020.

3. Dogra VS and Poblete J: Metaatatic carcinoid tumor in the liver. J Clin Ultrasound 21: 639-641, 1993.

4. Gustafsson BI, Kidd M and Modlin IM: Neuroendocrine tumors of the diffuse neuroendocrine system. Curr Opin Oncol 20: 1-12, 2008

5. Eltawil KM,Gustafsson BI,Kidd M and Modlin IM: Neuroendocrine tumors of the gallbladder: An evaluation and reassessment of management strategy. J Clin Gastroenterol 44: 687-695, 2010.

6. Rothenstein J, Cleary SP, Pond GR, Dale D, Gallinger S Moore MJ, Brierley J and Siu LL: Neuroendocrine tumors of the gastrointestinal tract: A decade of experience at the princess margaret hospital. Am J Clin Oncol 31: 64-70, 2008.

7. Oberg K: Diagnostic work-up of gastroenteropancreatic neuroendocrine tumors. Clinics (Sao Paulo) 67 (Suppl 1): S109-S112, 2012.

8. Yao JC, Hassan M, Phan A, Dagohoy C, Leary C, Mares JE, Abdalla EK, Fleming JB, Vauthey JN, Rashid A and Evans DB: One hundred years after 'carcinoid': Epidemiology of and prognostic factors for neuroendocrine tumors in 35,825 cases in the United States. J Clin Oncol 26: 3063-3072, 2008.

9. Kim J, Lee WJ, Lee SH, Lee KB, Ryu JK, Kim YT, Kim SW, Yoon YB, Hwang JH, Han HS, et al: Clinical features of 20 patients with curatively resected biliary neuroendocrine tumours. Dig Liver Dis 43: 965-970, 2011.

10. Lee JM, Hwang S, Lee SG, Lee YJ, Park KM, Kim KH, Ahn CS, Kim MH, Lee SK and Kim MW: Neuroendocrine tumors of the gallbladder: Twelve cases in a single institution. Hepatogastroenterology 57: 1064-1068, 2010.

11. Chiorean L, Bartos A, Pelau D, Iancu D, Ciuleanu T, Buiga R, Oancea I, Mangrau A, Iancu C and Badea R: Neuroendocrine tumor of gallbladder with liver and retroperitoneal metastases and a good response to the chemotherapeutical treatment. J Med Ultrason (2001) 42: 271-276, 2015.

12. Adachi T, Haraguchi M, Irie J, Yoshimoto T, Uehara R, Ito S, Tokai H, Noda K, Tada N, Hirabaru M, et al: Gallbladder smal cell carcinoma: A case report and literature review. Surg Case Rep 2: 71, 2016.
13. Yun SP, Shin N and Seo HI: Clinical outcomes of small cell neuroendocrine carcinoma and adenocarcinoma of the gallbladder. World J Gastroenterol 21: 269-275, 2015.

14. Duffy A, Capanu M, Abou-Alfa GK, Huitzil D, Jarnagin W, Fong Y, D'Angelica M, Dematteo RP, Blumgart LH and O'Reilly EM: Gallbladder cancer (GBC): 10-year experience at memorial sloan-kettering cancer center (MSKCC). J Surg Oncol 98: 485-489, 2008.

15. Komori Y, Yada K, Ohta M, Uchida H, Iwashita Y, Fukuzawa K, Kashima K, Yokoyama S, Inomata M and Kitano S: Mammalian target of rapamycin signaling activation patterns in pancreatic neuroendocrine tumors. J Hepatobiliary Pancreat Sci 21: 288-295, 2014

16. MissiagliaE,Dalai I,Barbi S, Beghelli S, Falconi M,della Peruta M, Piemonti L, Capurso G, Di Florio A, delle Fave G, et al: Pancreatic endocrine tumors: Expression profiling evidences a role for AKT-mTOR pathway. J Clin Oncol 28: 245-255, 2010.

17. Scoazec JY: Angiogenesis in neuroendocrine tumors: Therapeutic applications. Neuroendocrinology 97: 45-56, 2013.

18. Luttges J: What's new? The 2010 WHO classification for tumours of the pancreas. Pathologe 32 (Suppl 2): S332-S336, 2011 (In German).

19. Bosman FT, Camelr F, Hruban RH and Theise ND: World Health Organization classification of tumours of the digestive system [M]. IARC Press, Lyon, pp195-334, 2010.

20. Ayabe RI, Wach M, Ruff S, Martin S, Diggs L, Wiemken T, Hinyard L, Davis JL, Luu C and Hernandez JM: Primary gallbladder neuroendocrine tumors: Insights into a rare histology using a large national database. Ann Surg Oncol 26: 3577-3585, 2019.

21. Bae JS, Kim SH, Yoo J, Kim H and Han JK: Differential and prognostic MRI features of gallbladder neuroendocrine tumors and adenocarcinomas. Eur Radiol: Feb 5, 2020 (Epub ahead of print). doi: 10.1007/s00330-019-06588-9.

22. Moskal TL, Zhang PJ and Nava HR: Small cell carcinoma of the gallbladder. J Surg Oncol 70: 54-59, 1999.

23. Fujimoto G, Yamada S, Kusanagi H and Uegami W: Rapidly growing neuroendocrine carcinoma of the gallbladder: A case report. Radiol Case Rep 15: 259-265, 2020.

24. Chakrabarti D, Qayoom S, Ghosh A and Gupta R: Neuroendocrine carcinoma of the gall bladder in a young lady presenting with upper abdominal heaviness: A common complaint and a rare diagnosis. BMJ Case Rep 12: e229684, 2019.

25. Skalický A, Vištejnová L, Dubová M, Malkus T, Skalický T and Troup O: Mixed neuroendocrine-non-neuroendocrine carcinoma of gallbladder: Case report. World J Surg Oncol 17: 55, 2019.

26. Shimono C, Suwa K, Sato M, Shirai S, Yamada K, Nakamura Y and Makuuchi M: Large cell neuroendocrine carcinoma of the gallbladder: Long survival achieved by multimodal treatment. Int J Clin Oncol 14: 351-355, 2009.

27. Neyaz A, Husain N, Gupta S, Kumari S, Arora A, Awasthi NP, Malhotra KP and Misra S: Investigation of targetable predictive and prognostic markers in gallbladder carcinoma. J Gastrointest Oncol 9: 111-125, 2018.

28. Adachi T, Haraguchi M, Irie J, Yoshimoto T, Uehara R, Ito S, Tokai H, Noda K, Tada N, Hirabaru M, et al: Gallbladder small cell carcinoma: A case report and literature review. Surg Case Rep 2: 71, 2016.

29. Nishigami T, Yamada M, Nakasho K, Yamamura M, Satomi M, Uematsu K, Ri G, Mizuta T and Fukumoto H: Cacinoid tumor of the gall bladder. Intern Med 35: 953-956, 1996.

30. Handra-Luca A: Gallbladder neuroendocrine carcinoma: Metastasis or synchronous tumor? Minerva Chir 73: 619-620, 2018.

31. Liu W, Chen W, He X, Qu Q, Hong T and Li B: Cholecystectomy with gallbladder bed cautery might be sufficient for T1bN0M0 neuroendocrine carcinoma of gallbladders: Cases report and literature review. Medicine (Baltimore) 96: e8778, 2017.

32. Hussain I, Sarvepalli D, Zafar H, Jehanzeb S and Ullah W: Neuroendocrine tumor: A rare, aggressive tumor of the gallbladder. Cureus 11: e5571, 2019.

33. Liu W, Chen W, Chen J, Hong T, Li B, Qu Q and He X: Neuroendocrine carcinoma of gallbladder: A case series and literature review. Eur J Med Res 24: 8, 2019.

34. Soga J: Carcinoids and their variant endocrinomas. An analysis of 11,842 reported cases. J Exp Clin Cancer Res 22: 517-530, 2003.

35. Yadav R, Jain D, Mathur SR and Iyer VK: Cytomorphology of neuroendocrine tumours of the gallbladder. Cytopathology 27: 97-102, 2016 
36. Peracchi M, Gebbia C, Basilisco G, Quatrini M, Tarantino C, Vescarelli C, Massironi S and Conte D: Plasma chromogranin A in patients with autoimmune chronic atrophic gastritis, enterochromaffin-like cell lesions and gastric carcinoids. Eur J Endocrinol 152: 443-448, 2005.

37. Monier A, Saloum N, Szmigielski W, Alrashid A and Napaki SM Neuroendocrine tumor of the gallbladder. Pol J Radiol 80: 228-231, 2015.

38. Leem G, Chung MJ, Park JY, Bang S, Song SY, Chung JB and Park SW: Clinical value of contrast-enhanced harmonic endoscopic ultrasonography in the differential diagnosis of pancreatic and gallbladder masses. Clin Endosc 51: 80-88, 2018.

39. Sugimoto M, Takagi T, SuzukiR, KonnoN, AsamaH, Watanabe K, Nakamura J, Kikuchi H, Waragai Y, Takasumi M, et al: Contrast-enhanced harmonic endoscopic ultrasonography in gallbladder cancer and pancreatic cancer. Fukushima J Med Sci 63: 39-45, 2017.

40. Reimão S, Francioni E, Bories E, Caillol F, Pesenti C and Giovannini M: Endoscopic ultrasonography-guided bi-lateral biliary drainage: A case series study. Endosc Ultrasound 3 (Suppl 1): S18, 2014.

41. Samad A, Kaplan A, Arain M, Attam R, Jessurun J, Manivel JC and Pambuccian SE: Endoscopic ultrasound-guided fine-needle aspiration diagnosis of large cell neuroendocrine carcinoma of the gallbladder and common bile duct: Report of a case. Diagn Cytopathol 41: 1091-1095, 2013.

42. Abutaka A, El-Matbouly M, Helmy I, Elmoghazy W, Sulieman I, Ben Gashir M, Soofi M, Khalaf H and Elaffandi A: Repeat liver resection for pure large cell neuroendocrine carcinoma of the gallbladder: A favorable outcome. World J Surg Oncol 17: 126, 2019.

43. Iype S, Mirza TA, Pmpper DJ, Bhattacharya S, Feakins RM and Kocher HM: Neuroendocrine tumours of the gaHbladder: Three cases and a review of the literature. Postgrad Med J 85: 213-218, 2009

44. Hirose Y, Sakata J, Endo K, Takahashi M, Saito R, Imano H, Kido T, Yoshino K, Sasaki T and Wakai T: A 0.8-cm clear cell neuroendocrine tumor G1 of the gallbladder with lymph node metastasis: A case report. World J Surg Oncol 16: 150, 2018.

45. You YH, Choi DW, Heo JS, Han IW, Choi SH, Jang KT and Han S: Can surgical treatment be justified for neuroendocrine carcinoma of the gallbladder? Medicine (Baltimore) 98: e14886, 2019.

46. Sun YW and Liu DJ: Neuroendocrine carcinoma of the gallbladder. Chin J Pract Surg 31: 265-267, 2011 (In Chinese).

47. Garg PK, Pandey D and Sharma J: The surgical management of gallbladder cancer. Expert Rev Gastroenterol Hepatol 9: 155-166, 2015.

48. Machairas N, Paspala A, Frountzas M, Tsilimigras DI, Moris D, Ntomi V, Tsapralis D and Schizas D: Mixed adenoneuroendocrine carcinoma (MANEC) of the gallbladder: A systematic review of outcomes following surgical management. In Vivo 33 1721-1726, 2019.

49. Elm'hadi C, Zerrik M, Errihani H and Ichou M: A long survival woman with primary small-cell carcinoma of the gallbladder: Role of chemotherapy maintenance. Cureus 9: e1368, 2017.

50. Shoushtari AN, Bluth MJ, Goldman DA, Bitas C, Lefkowitz RA, Postow MA, Munhoz RR, Buchar G, Hester RH, Romero JA, et al Clinical features and response to systemic therapy in a historical cohort of advanced or unresectable mucosal melanoma. Melanoma Res 27: 57-64, 2017

51. Tani S, Yamagishi S, Fukunaga K, Morita M, Sonoda T, Murao S Ikuta S, Kakuno A and Yamanaka N: A case of disease-free, long survival in a patient with mixed adenoneuroendocrine carcinoma of the gallbladder treated with induction CDDP/CPT-11 chemotherapy and resection. Gan To Kagaku Ryoho 42: 113-117, 2015 (In Japanese).

52. Smith JL and Davis BR: Neuroendocrine tumor of the gallbladder treated with neoadjuvant chemotherapy and surgery. Am Surg 80: 318-320, 2014

53. Elahi F, Ahmadzadeh A, Yadonahzadeh M, Hassanpour K and Babaei M: Neuroendocrine tumor of the gallbladder. Arch Iran Med 16: 123-125, 2013.

54. Okuyama Y, Fukui A, Enoki Y, Morishita H, Yoshida N and Fujimoto S: A large cell neuroendocrine carcinoma of the gall bladder: Diagnosis with ${ }^{18}$ FDGPET/CT-guided biliary cytology and treatment with combined chemotherapy achieved a long-term stable condition. Jpn J Clin Oncol 43: 571-574, 2013.

55. Inoue D, Ozaka M, Muramatsu Y, Yamada I, Matsuyama M, Kanda $\mathrm{H}$ and Ishii $\mathrm{H}$ : Neuroendocrine gallbladder cancer treated with cisplatin plus irinotecan-A case report. Gan To Kagaku Ryoho 41: 765-767, 2014 (In Japanese).
56. Barakat MT, Meeran K and Bloom SR: Neuroendocrine tumours . Endocr Relat Cancer 11: 1-18, 2004.

57. Pavel ME, Hassler G, Baum U, Hahn EG, Lohmann T and Schuppan D: Circulating levels of angiogenic cytokines can predict tumour progression and prognosis in neuroendocrine carcinomas. Clin Endocrinol (Oxf) 62: 434-443, 2005

58. Raymond E, Dahan L, Raoul JL, Bang YJ, Borbath I, Lombard-Bohas C, Valle J, Metrakos P, Smith D, Vinik A, et al: Sunitinib malate for the treatment of pancreatic neuroendocrine tumors. N Engl J Med 364: 501-513, 2011.

59. Yao JC, Shah MH, Ito T, Bohas CL, Wolin EM, Van Cutsem E, Hobday TJ, Okusaka T, Capdevila J, de Vries EG, et al: Everolimus for advanced pancreatic neuroendocrine tumors. N Engl J Med 364: 514-523, 2011.

60. Caplin ME, Pavel M, Cwikla JB, Phan AT, Raderer M, Sedláčková E, Cadiot G, Wolin EM, Capdevila J, Wall L, et al: Lanreotide in metastatic enteropancreatic neuroendocrine tumors. N Engl J Med 371: 224-233, 2014.

61. Igaz P: Efficacy of somatostatin analogues in the treatment of neuroendocrine tumours based on the results of recent clinical trials. Orv Hetil 155: 1908-1912, 2014 (In Hungarian).

62. Oberg K, Akerstrom $G$, Rindi $G$ and Jelic S; ESMO Guidelines Working Group: Neuroendocrine gastroenteropancreatic tumours: ESMO clinical practice guidelines for diagnosis,treatment and follow-up. Ann Oncol 21 (Suppl 5): v223-v227, 2010

63. Lin PC, Lai YC, Lai JI, Hsu SY and Wang WS: Successful treatment of gallbladder neuroendocrine carcinoma with combined chemo-radiotherapy: A case report and literature review. Int J Clin Pharmacol Ther 49: 403-408, 2011.

64. Kwekkeboom DJ, de Herder WW, Kam BL, van Eijck CH, van Essen M, Kooij PP, Feelders RA, van Aken MO and Krenning EP: Treatment with the radiolabeled somatostatin analog [177 Lu-DOTA 0, Tyr3] octreotate: Toxicity, efficacy, and survival. J Clin Oncol 26: 2124-2130, 2008.

65. Roversi R, Ricci S, Rossi G, Roversi M and Cavallo G: Locoregional therapy with hypoxic liver perfusion in malignant neoplasms of the gallbladder. Preliminary experience. Radiol Med 94: 220-225, 1997 (In Italian).

66. Garin E, Rolland Y, Boucher E, Ardisson V, Laffont S, Boudjema K, Bourguet P and Raoul JL: First experience of hepatic radioembolization using microspheres labelled with yttrium-90 (TheraSphere): Practical aspects concerning its implementation. Eur J Nucl Med Mol Imaging 37: 453-461, 2010.

67. Kamei K, Shindoh J, Kiya Y, Matsumoto I, Hashimoto M and Takeyama Y: Conversion surgery after extensive chemotherapy for stage IV mixed adenoneuroendocrine carcinoma (MANEC) of the gallbladder: Clinical implications from the patterns of response and recurrence. Clin J Gastroenterol: Oct 15, 2019 (Epub ahead of print). doi: 10.1007/s12328-019-01053-y.

68. Salimi $Z$ and Sharafuddin M: Ultrasound appearance of primary carcinoid tumor of the gallbladder associated with carcinoid syndrome. J Clin Ultrasound 23: 435-437, 1995.

69. Soga J: Primary endocrinomas (carcinoids and variant neoplasms) of the gallbladder: A statistical evaluation of 138 reported cases. J Exp Clin Cancer Res 22: 5-15, 2003.

70. Pantongrag-Brown L, Buetow PC, Carr NJ, Lichtenstein JE and Buck JL: Calcification and fibrosis in mesenteric carcinoid tumor: CT findings and pathologic correlation. AJR Am J Roentgenol 164: 387-391, 1995.

71. Shapera E and Bitting C: Survival: A rare outcome in large cell neuroendocrine carcinoma of the gallbladder. Acta Gastroenterol Belg 82: 433-436, 2019.

72. Deshmukh SD, Gulati HK, Gaopande V, Purandare S and Anand M: Incidental cystic endocrine tumor of the pancreas: A case report with immunohistochemical study. J Cancer Res Ther 8: 289-291, 2012.

73. Iwasa S, Morizane C, Okusaka T, Ueno H, Ikeda M, Kondo S, Tanaka T, Nakachi K, Mitsunaga S, Kojima Y, et al: Cisplatin and etoposide as first-line chemotherapy for poorly differentiated neuroendocrine carcinoma of the hepatobiliary tract and pancreas. Jpn J Clin Oncol 40: 313-318, 2010.

This work is licensed under a Creative Commons Attribution-NonCommercial-NoDerivatives 4.0 International (CC BY-NC-ND 4.0) License. 